\title{
Historical Inductions, Unconceived Alternatives, and Unconceived Objections
}

Moti Mizrahi

motimizra@gmail.com

Forthcoming in Journal for General Philosophy of Science

\begin{abstract}
In this paper, I outline a reductio against Stanford's "New Induction" on the History of Science, which is an inductive argument against scientific realism that is based on what Stanford (2006) calls "the Problem of Unconceived Alternatives" (PUA). From the supposition that Stanford's New Induction on the History of Science is cogent, and the parallel New Induction on the History of Philosophy (Mizrahi 2014), it follows that scientific antirealism is not worthy of belief. I also show that denying a key premise in the reductio only forces antirealists who endorse Stanford's New Induction on the History of Science into a dilemma: either antirealism falls under the axe of Stanford's New Induction on the History of Science or it falls under the axe of the New Induction on the History of Philosophy.
\end{abstract}

Keywords: antirealism; new induction; pessimistic induction; problem of unconceived alternatives; problem of unconceived objections; scientific realism

\section{Introduction}

One of the key arguments against scientific realism is known as the pessimistic induction (or the pessimistic meta-induction). According to this argument, there are scientific theories that were successful, i.e., they made novel predictions that were borne out by observations or experimentation, but that are now considered to be strictly false. As Lipton puts it:

The history of science is a graveyard of theories that were empirically successful for a time, but are now known to be false, and of theoretical entities - the crystalline spheres, phlogiston, caloric, the ether and their ilk-that we now know do not exist. Science does not have a good track record for truth, and this provides the basis for a simple empirical generalization. Put crudely, all past theories have turned out to be false, therefore it is probable that all present and future theories will be false as well. That is the pessimistic induction (Lipton 2005, 1265).

The historical premise of this inductive argument is often supported by a list that Laudan complied in his (1981). Here is Laudan's list:

- the crystalline spheres of ancient and medieval astronomy;

- the humoral theory of medicine;

- the effluvial theory of static electricity; 
- 'catastrophic' geology, with its commitment to a universal (Noachian) deluge;

- the phlogiston theory of chemistry'

- the caloric theory of heat;

- the vibratory theory of heat;

- the vital force theories of physiology;

- the electromagnetic aether;

- the optical aether;

- the theory of circular inertia;

- theories of spontaneous generation (Laudan 1981, 33).

However, as Park (2011) and I (2013) have argued, since Laudan's (1981) list is not a random sample of successful but false theories, which means that it cannot be a representative sample of scientific theories, any inductive argument that is based on Laudan's (1981) list commits the fallacy of biased statistics. That is, an inductive argument from a sample that is based on Laudan's list is a bad inductive generalization because it commits the "fallacy of biased statistics" (Park 2011, 83) and because the "theories on Laudan's list were not randomly selected, but rather were cherry-picked in order to argue against a thesis of scientific realism" (Mizrahi 2013, 3220).

Another historical induction against scientific realism was put forward by Stanford (2006). Like Laudan's pessimistic induction, Stanford's $(2006,19)$ New Induction is an "induction over the history of science" (original emphasis). According to Stanford (2006, 20), "the history of scientific inquiry itself offers a straightforward rationale for thinking that there typically are alternatives to our best theories equally well confirmed by the evidence, even when we are unable to conceive of them at the time." Stanford calls this the Problem of Unconceived Alternatives (PUA). Based on the PUA, Stanford advances an inductive argument he calls the "New Induction" on the History of Science, ${ }^{1}$ which Magnus reconstructs as follows:

\section{A New Induction on the History of Science}

NI-1 The historical record reveals that past scientists typically failed to conceive of alternatives to their favorite, then-successful theories.

NI-2 So, present scientists fail to conceive of alternatives to their favorite, nowsuccessful theories.

NI-3 Therefore, we should not believe our present scientific theories insofar as they are the result of eliminative inference (Magnus 2010, 807).

If Stanford's New Induction on the History of Science is cogent, then what Psillos $(2006,135)$ calls "the epistemic thesis of scientific realism," i.e., that "mature and predictively successful scientific theories are well-confirmed and approximately true" (cf. Psillos 1999, xix), is not worthy of belief. In other words, realists think that at least successful scientific theories warrant an attitude of belief in their approximate truth, whereas antirealists (including those who endorse

\footnotetext{
${ }^{1}$ For criticisms of Stanford's PUA and his New Induction, see Magnus (2006) and (2010), Chakravartty (2008), Godfrey-Smith (2008), Devitt (2011), Ruhmkorff (2011), and Egg (2014).
} 
Stanford's New Induction on the History of Science) think that the proper attitude to take with respect to scientific theories, even successful ones, is agnosticism.

Now, I have argued elsewhere that there is a problem parallel to the PUA that applies to Western Philosophy.

In much the same way that "the history of scientific inquiry itself offers a straightforward rationale for thinking that there typically are alternatives to our best theories equally well confirmed by the evidence, even when we are unable to conceive of them at the time" (Stanford 2006, p. 20), the history of philosophical inquiry offers a straightforward rationale for thinking that there typically are serious objections to our best philosophical theories, even when we are unable to conceive of them at the time. In other words, the historical record shows that philosophers have typically failed to conceive of serious objections to their well-defended philosophical theories. As the historical record also shows, however, other philosophers subsequently conceived of serious objections to those well-defended philosophical theories (Mizrahi 2014, 426-427; original emphasis).

To the list of philosophical theories that subsequently faced serious objections in my $(2014,427)$, we can add the following:

Table 1. Some philosophical theories that were met with serious objections.

\begin{tabular}{|l|l|l|}
\hline & Philosophical Theory & Serious Objection \\
\hline 1 & $\begin{array}{l}\text { Plato's theory of the Forms } \\
\text { (e.g., Parmenides 128e-130a) }\end{array}$ & $\begin{array}{l}\text { The third man argument (Parmenides 132a-b and } \\
\text { Aristotle's Metaphysics 990b17) }\end{array}$ \\
\hline 2 & $\begin{array}{l}\text { Analytic/Synthetic distinction } \\
\text { (Kant 1781/1998) }\end{array}$ & $\begin{array}{l}\text { Quine (1953/1980): no principled way to draw an } \\
\text { analytic/synthetic distinction }\end{array}$ \\
\hline 3 & $\begin{array}{l}\text { Normative hedonism (Bentham } \\
1789)\end{array}$ & $\begin{array}{l}\text { Nozick (1974): thoughts and memories of pleasure are not } \\
\text { necessarily pleasurable }\end{array}$ \\
\hline 4 & The Turing Test (Turing 1950) & Block's (1981) 'Blockhead" thought experiment \\
\hline 5 & Behaviorism (Skinner 1974) & $\begin{array}{l}\text { Chomsky (1959) and (1971): Behaviorism cannot account } \\
\text { for lexical explosion; language learning is not a matter of } \\
\text { reinforcement }\end{array}$ \\
\hline 6 & $\begin{array}{l}\text { Trope Primitivism (Williams } \\
\text { 1966) }\end{array}$ & $\begin{array}{l}\text { Williamsonian tropes are constructed out of something } \\
\text { else and thus are incompatible with primitivism } \\
\text { (Armstrong 2005) }\end{array}$ \\
\hline
\end{tabular}

In fact, one could argue that the most plausible way to construe progress in Western Philosophy is in terms of figuring out which theories are false or implausible (Mironov 2013). Be that as it may, if Stanford's PUA provides the basis for a New Induction on the History of Science, then the PUO provides the basis for a New Induction on the History of Philosophy. The New Induction on the History of Philosophy, then, runs as follows: 


\section{A New Induction on the History of Philosophy}

NIP-1 The historical record reveals that past Western philosophers typically failed to conceive of serious objections to their favorite, then-defensible theories.

NIP-2 So, present Western philosophers fail to conceive of serious objections to their favorite, now-defensible theories.

NIP-3 Therefore, we should not believe our present philosophical theories [insofar as their defensibility is due in part to serious objections being unconceived] (Mizrahi 2014, 427-428).

The PUO for philosophical theories, then, is analogous to Stanford's PUA for scientific theories (Mizrahi 2014, 428-429). This is because an alternative scientific theory $T_{2}$ that accounts for the phenomena just as well as $T_{1}$ amounts to a serious objection against $T_{1}$. In other words, "alternatives : scientific theories :: objections : philosophical theories" (Mizrahi 2014, 428).

In that respect, it is important to note that Stanford's PUA is supposed to point to a real problem in the history of science, not merely to a logical problem. That is to say, Stanford's PUA is not merely a logical problem of failing to conceive of logically possible alternatives to thenwell-confirmed theories. Rather, Stanford's PUA is a real problem of failing to conceive of empirically viable alternatives to then-well-confirmed theories, which turned out to be equally confirmed by the evidence. This is because, for Stanford, an unconceived alternative is a competing theory that is "well confirmed by the body of actual evidence we have in hand" (Stanford 2006, 18). That is, a mere logical possibility is not an unconceived alternative because it is not a competing theory that is "well confirmed by the body of actual evidence we have in hand." For example, the hypothesis that the universe is accelerating because God is blowing wind on galaxies is not an unconceived alternative to the dark energy hypothesis because it is not confirmed (let alone well confirmed) by the body of actual evidence we have in hand. On the other hand, the Tychonic system was an empirically viable alternative, not merely a logical possibility, and hence a serious contender and a serious objection to the heliocentric model. For this reason, it will do scientific antirealists who endorse Stanford's New Induction on the History of Science no good to object to the New Induction on the History of Philosophy by saying that some (not yet conceived) objections lack the power to undermine now-defensible theories.

Since empirically viable alternatives to then-well-confirmed scientific theories that turned out to be equally confirmed by the evidence amount to serious objections to those scientific theories, Stanford's PUA and the PUO are analogous problems that provide support for parallel inductive arguments from the History of Science and the History of Philosophy, respectively. The parallels between Stanford's New Induction on the History of Science and the New Induction on the History of Philosophy can be seen as follows:

NI-1 [/NIP-1] The historical record reveals that past scientists [/philosophers] typically failed to conceive of alternatives [/serious objections] to their favorite, then-successful [/then-defensible] theories.

NI-2 [/NIP-2] So, present scientists [/philosophers] fail to conceive of alternatives [/serious objections] to their favorite, now-successful [/now-defensible] theories. 
NI-3 [/NIP-3] Therefore, we should not believe our present scientific [/philosophical] theories insofar as they are the result of eliminative inference [/insofar as their defensibility is due in part to serious objections being unconceived].

Given these parallels between Stanford's New Induction on the History of Science and the New Induction on the History of Philosophy, the following objection against the PUO and the New Induction on the History of Philosophy is also misguided: unlike alternative theories, serious objections to a received philosophical theory do not "kill off" that theory or undermine its epistemic status.

The case of the geocentric, heliocentric, and Tychonic systems shows that in science it is sometimes the case that alternative theories do not "kill off" a favorite theory, just as in philosophy it is sometimes the case that serious objections do not "kill off" a favorite theory. In Western Philosophy, as in science, philosophers sometimes "fall in love" with a particular theory, in which case even serious objections would not be taken to "kill off" the favorite theory of the day. As Blackburn puts it:

when the historical moment is right [philosophers] fall in love with the conclusions, and any blemish in the argument is quickly forgiven: the most outright fallacy becomes beatified as a bold and imaginative train of thought, obscurity actually befits a deep original exploration of dim and unfamiliar interconnexions, arguments that nobody can follow at all become a brilliant roller-coaster ride towards a shift in the vocabulary, a reformulation of the problem space (Blackburn 2005; emphasis added).

Of course, since Kuhn (1962), philosophers, historians, and sociologists of science have made similar observations about science, namely, that factors other than truth and argumentation have an effect on whether a theory is accepted or not (see, e.g., Douglas 2009.) Moreover, the case of the discovery of Neptune shows that, in science, too, scientists sometimes defend theories even in the face of what appears to be contrary evidence. Before the discovery of Neptune, it was the observed orbit of Uranus that did not fit with the predictions of Newton's theory (Okasha 2002, 15. Cf. Bamford 1996).

With the PUO and the New Induction on the History of Philosophy in hand, we are now in a position to see what the reductio against Stanford's New Induction on the History of Science looks like.

\section{A Reductio against Stanford's New Induction on the History of Science}

Given the PUO and the New Induction on the History of Philosophy, I think that scientific antirealists who endorse Stanford's PUA and his New Induction on the History of Science face the following problem: given the parallels between Stanford's New Induction on the History of Science and the New Induction on the History of Philosophy, if the former is a cogent argument against scientific realism, i.e., the epistemic thesis of scientific realism according to which "mature and predictively successful scientific theories are well-confirmed and approximately true" (Psillos 2006, 135), then the latter is a cogent argument against philosophical realism. If that is the case, however, then it follows that scientific antirealism is not worthy of belief, since scientific antirealism is a philosophical theory. More explicitly: 
(1) Stanford's New Induction on the History of Science is a cogent argument against scientific realism. [Assumption for reductio]

(2) If Stanford's New Induction on the History of Science is a cogent argument against scientific realism, then the New Induction on the History of Philosophy is a cogent argument against philosophical realism. [Premise]

(3) $\therefore$ The New Induction on the History of Philosophy is a cogent argument against philosophical realism. [from (1) \& (2) by modus ponens]

(4) If the New Induction on the History of Philosophy is a cogent argument against philosophical realism, then, if scientific antirealism is a philosophical theory, we should not believe it. [Premise]

(5) $\therefore$ If scientific antirealism is a philosophical theory, we should not believe it. [from (3) \& (4) by modus ponens]

(6) Scientific antirealism is a philosophical theory. [Premise]

(7) $\therefore$ We should not believe scientific antirealism. [from (5) \& (6) by modus ponens]

Of course, scientific antirealists who endorse Stanford's New Induction on the History of Science cannot accept (7), since (7) says that they should not believe their own position. In the next section, I will consider several objections to this reductio. ${ }^{2}$

\section{Objections and Replies}

Since the reductio outlined in Section 2 is deductively valid, scientific antirealists who endorse Stanford's New Induction on the History of Science might try to block the inference to (7) by objecting to one or all of the premises, namely, (2), (4), and (6). Premise (2) has been discussed in Section 1 above and is supported by the parallels between Stanford's PUA and the New Induction on the History of Science and the PUO and the New Induction on the History of Philosophy. In what follows, then, I will defend premises (4) and (6) of the aforementioned reductio.

Premise (4) simply states that, if scientific antirealism is a philosophical theory, then the conclusion of the New Induction on the History of Philosophy applies to it, since that conclusion applies to all philosophical theories. More explicitly, if the New Induction on the History of Philosophy is a cogent argument against philosophical realism, then, if scientific antirealism is a philosophical theory, we should not believe it, since the New Induction on the History of Philosophy shows that we should not believe our present philosophical theories.

\footnotetext{
${ }^{2}$ It is worth noting that, for this reductio to go through, there is no need to assume that Stanford's New Induction on the History of Science is an argument for antirealism (in particular, his own brand of antirealism, namely, "epistemic instrumentalism"). All that needs to be assumed is that, at the very least, Stanford's New Induction on the History of Science is supposed to be an argument against scientific realism, where scientific realism here refers to the epistemic thesis according to which "mature and predictively successful scientific theories are well-confirmed and approximately true" (Psillos 2006, 135). On the PUA as an argument against scientific realism, see Magnus (2006) and (2010), Chakravartty (2008), Godfrey-Smith (2008), Devitt (2011), Ruhmkorff (2011), Egg (2014), and Rowbottom (forthcoming).
} 
The crucial question for present purposes, then, is whether or not scientific antirealism is a philosophical theory. According to premise (6), scientific antirealism is a philosophical theory, which is why it falls under the scope of the conclusion of the New Induction on the History of Philosophy. So why think that scientific antirealism is a philosophical theory? Following Psillos $(2006,135)$, I have taken the epistemic thesis of scientific realism to be the thesis that "Mature and predictively successful scientific theories are well-confirmed and approximately true." ${ }^{3}$ On the other hand:

The term 'antirealism' (or 'anti-realism') encompasses any position that is opposed to realism along one or more of the [following] dimensions [...]: the metaphysical commitment to the existence of a mind-independent reality; the semantic commitment to interpret theories literally or at face value; and the epistemological commitment to regard theories as constituting knowledge of both observables and unobservables (Chakravartty 2013; emphasis added).

Since Stanford's New Induction on the History of Science is supposed to be an argument against the epistemological dimension of scientific realism, scientific antirealism, for present purposes, is the following thesis:

(AR) We should not believe that present scientific theories are approximately true.

Now, the question is whether or not (AR) is a philosophical theory. The question of what makes a theory a philosophical theory is not an easy one to answer and it is surely beyond the scope of this paper. So I will not attempt to take on this question here. For present purposes, it is enough to make three points. First, if normativity is the mark of the philosophical, then (AR) is a philosophical theory, since it is a normative thesis insofar as it tells us what we should (or should not) believe. Second, (AR) is a key tenet of constructive empiricism, according to which, "Science aims to give us theories that are empirically adequate" (van Fraassen 1980, 12), not theories that are approximately true. One would be hard pressed to deny that constructive empiricism is a philosophical theory. Third, if scientific realism, which recommends an attitude of belief in the approximate truth of our best scientific theories, is a philosophical theory, then (AR), which recommends an attitude of non-belief or agnosticism about the approximate truth of our best scientific theories, is a philosophical theory as well.

To this it might be objected that scientific antirealism, i.e., (AR), is supposed to be a scientific theory, not a philosophical theory. Some might think that this is so because antirealism is supported by a "scientific" argument from a sample (or inductive generalization), namely, the pessimistic induction. The problem with this objection is not only that there are serious problems with the pessimistic induction ${ }^{4}$ but also that it is a bad "scientific" argument. As mentioned in

\footnotetext{
${ }^{3}$ Note that nothing here hangs on whether scientific realists want to be more selective about their realism. The epistemic thesis can be restated to accommodate this sort of selectiveness. For example, scientific realists who want to be realists about some mature and successful theories, but not others, can endorse the following version of the epistemic thesis: "Mature and predictively successful theory $T$ is well-confirmed and approximately true." Scientific realists who prefer the divide et impera strategy (e.g., Kitcher 2001, 18 and Psillos 1999, 106) can endorse the following version of the epistemic thesis: "The theoretical claims of mature and predictively successful theory $T$ that refer to the working (as opposed to idle) posits of $T$ are well-confirmed and approximately true." Cf. Cordero (2011).

${ }^{4}$ See, for example, Lewis (2001) and Lange (2002).
} 
Section 1, the pessimistic induction is a bad "scientific" argument against scientific realism because it is a bad inductive generalization. The pessimistic induction is a bad inductive generalization because it commits the "fallacy of biased statistics" (Park 2011, 83), because "the joint sample set of all examples of refuted theories offered by antirealists is not representative" (Fahrbach 2011, 151), and because the "theories on Laudan's list were not randomly selected, but rather were cherry-picked in order to argue against a thesis of scientific realism" (Mizrahi 2013, 3220).

In that respect, it is important to note that the pessimistic induction (the argument discussed in Section 1) is not the same argument as Stanford's New Induction on the History of Science. Indeed, Stanford $(2006,18)$ is careful to distinguish his "New Induction" from "the traditional pessimistic induction." As he writes:

Recall that the classical pessimistic induction notes simply that past successful theories have tuned out to be false and suggests that we have no reason to think that present successful theories will not suffer the same fate. By contrast, I propose what I will call the new induction over the history of science: that we have, throughout the history of scientific inquiry and in virtually every scientific field, repeatedly occupied an epistemic position in which we could conceive of only one or a few theories that were well confirmed by the available evidence, while subsequent inquiry would routinely (if not invariably) reveal further, radically distinct alternatives as well confirmed by the previously available evidence as those we were inclined to accept on the strength of that evidence (Stanford 2006, 19; original emphasis).

Park's (2011), Fahrbach's (2011), and my (2013) objections against the pessimistic induction, then, may or may not apply to Stanford's New Induction. However, insofar as the "classical" pessimistic induction is supposed to be an argument for antirealism, and given that it is a bad inductive generalization, as Park (2011), Fahrbach (2011), and I (2013) argue, it follows that a bad "scientific" argument is advanced in support of antirealism.

More importantly, however, if antirealists were to claim that (AR) is a scientific, not a philosophical, theory, they would face the following dilemma. Since the conclusion of Stanford's New Induction on the History of Science says that we should not believe our present scientific theories, if (AR) is a scientific theory, then we should not believe it by Stanford's own lights. Indeed, if (AR) is a philosophical theory, then it falls prey to the New Induction, since the conclusion of the New Induction is that we should not believe our present philosophical theories. And if (AR) is a scientific theory, then it falls prey to Stanford's New Induction, since the conclusion of Stanford's New Induction is that we should not believe our present scientific theories. More explicitly:

Either (AR) is a scientific theory or (AR) is a philosophical theory.

If (AR) is a scientific theory, then we should not believe it. [from NI-3]

If (AR) is a philosophical theory, then we should not believe it. [from NIP-3]

$\therefore$ Whether (AR) is a scientific or a philosophical theory, we should not believe it. 
If this dilemma is sound, then it actually does not matter whether (AR) is a scientific theory or a philosophical theory; we should not believe it anyway.

Finally, although my aim in this paper is not to defend scientific realism, but rather to expose what I take to be problems with Stanford's New Induction on the History of Science, it is important to note that one cannot run a reductio like the one outlined in Section 2 against scientific realism. This is so because scientific realists reject the supposition that Stanford's New Induction on the History of Science is a cogent argument against scientific realism (see, e.g., Devitt 2011). So a parallel reductio against scientific realism does not get off the ground, since scientific realists reject (1) in the reductio outlined in Section 2, and thus are not committed to (3). On the other hand, those scientific antirealists who think that Stanford's New Induction on the History of Science is a cogent argument against scientific realism, i.e., those who accept (1), are thereby committed to the claim that the New Induction on the History of Philosophy is a cogent argument against philosophical realism, i.e., (3), given the aforementioned parallels between the two arguments, and thus that we should not believe scientific antirealism.

\section{Conclusion}

In this paper, I have argued that Stanford's New Induction on the History of Science faces the following problems. First, from the supposition that Stanford's New Induction on the History of Science is cogent, and the parallel New Induction on the History of Philosophy, it follows that scientific antirealism is not worthy of belief. Second, if antirealism is a scientific theory, then, by Stanford's New Induction on the History of Science, it should not be believed, whereas if antirealism is a philosophical theory, then, by the New Induction on the History of Philosophy, it should not be believed, either. If this is correct, then both the classical (namely, the pessimistic induction based on Laudan's list) and the new (namely, Stanford's New Induction based on the PUA) inductive arguments from the history of science against scientific realism fail to pose a serious challenge to scientific realism.

\section{Acknowledgments}

I am grateful to two anonymous reviewers of Journal for General Philosophy of Science for helpful comments on an earlier draft.

\section{References}

Armstrong, D. M. (2005). Four disputes about properties. Synthese, 144, 309-320.

Bamford, G. (1996). Popper and his commentators on the discovery of Neptune: a close shave for the law of gravitation. Studies in History and Philosophy of Science, 27, 207-232.

Bentham, J. (1789). An Introduction to the Principles of Morals and Legislation. 
Blackburn, S. (2005). Review of Donald Davidson, Truth and Predication. The New Republic (November 24, 2005). Available at http://www.powells.com/review/2005_11_24.html.

Block, N. (1981). Psychologism and behaviorism. Philosophical Review, 90, 5-43.

Chakravartty, A. (2008). What you don't know can't hurt you: realism and the unconceived. Philosophical Studies, 137, 149-158.

Chakravartty, A. (2013). Scientific Realism. In E. N. Zalta (ed.), The Stanford Encyclopedia of Philosophy (Summer 2013 Edition).

http://plato.stanford.edu/archives/sum2011/entries/scientific-realism.

Chomsky, N. (1959). Review of Verbal Behavior. Language, 35, 26-58.

Chomsky, N. (1971). The case against B. F. Skinner. New York Review of Books, 30, 18-24.

Cordero, A. (2011). Scientific realism and the divide et impera strategy: the ether saga revisited. Philosophy of Science, 78, 1120-1130.

Devitt, M. (2011). Are unconceived alternatives a problem for scientific realism? Journal for General Philosophy of Science, 42, 285-293.

Douglas, H. (2009). Science, Policy, and the Value-Free Ideal. Pittsburgh, PA: University of Pittsburgh Press.

Egg, M. (2014). Expanding our grasp: causal knowledge and the problem of unconceived alternatives. British Journal for the Philosophy of Science. DOI: 10.1093/bjps/axu025.

Fahrbach, L. (2011). How the growth of science ends theory change. Synthese, 180, 139-155.

Godfrey-Smith, P. (2008). Recurrent transient underdetermination and the glass half full. Philosophical Studies, 137, 141-148.

Kant, I. (1781/1998). Critique of Pure Reason. P. Guyer and A. W. Wood (trans.). Cambridge: Cambridge University Press.

Kitcher, P. (2001). Science, Truth, and Democracy. New York: Oxford University Press.

Kuhn, T. S. (1962). The Structure of Scientific Revolutions. Chicago: Chicago University Press.

Lange, M. (2002). Baseball, pessimistic inductions and the turnover fallacy. Analysis, 62, 281285.

Laudan, L. (1981). A confutation of convergent realism. Philosophy of Science, 48, 19-49.

Lewis, P. J. (2001). Why the pessimistic induction is a fallacy. Synthese, 129, 371-380.

Lipton, P. (2005). The truth about science. Philosophical Transactions of the Royal Society B, 360, 1259-1269.

Magnus, P. D. (2006). What's new about the new induction? Synthese, 148, 295-301. 
Magnus, P. D. (2010). Inductions, red herrings, and the best explanation for the mixed record of science. British Journal for the Philosophy of Science, 61, 803-819.

Mironov, V. (2013). On progress in philosophy. Metaphilosophy, 44, 10-14.

Mizrahi, M. (2013). The pessimistic induction: a bad argument gone too far. Synthese, 190, 3209-3226.

Mizrahi, M. (2014). The problem of unconceived objections. Argumentation, 28, 425-436.

Nozick, R. (1974). Anarchy, State, and Utopia. Oxford: Basil Blackwell.

Okasha, S. (2002). Philosophy of Science: A Very Short Introduction. New York: Oxford University Press.

Park, S. (2011). A confutation of the pessimistic induction. Journal for General Philosophy of Science, 42, 75-84.

Plato. (1997). Parmenides. In M. J. Cooper (ed.), Plato: Complete Works. Indianapolis: Hackett Publishing Co.

Psillos, S. (1999). Scientific Realism: How Science Tracks Truth. London: Routledge.

Psillos, S. (2006). Thinking about the ultimate argument for realism. In C. Cheyne and J. Worrall (eds.), Rationality \& Reality: Essays in Honour of Alan Musgrave (pp. 133-156). Dordrecht: Springer.

Quine, W. (1953/1980). From a Logical Point of View. 2nd ed. Cambridge, MA: Harvard University Press.

Rowbottom, D. P. (forthcoming). Extending the argument from unconceived alternatives: observations, models, predictions, explanations, methods, instruments, experiments, and values. Synthese.

Ruhmkorff, S. (2011). Some difficulties for the problem of unconceived alternatives. Philosophy of Science, 78, 875-886.

Skinner, B. F. (1974). About Behaviorism. New York: Vintage.

Stanford, P. K. (2006). Exceeding Our Grasp: Science, History, and the Problem of Unconceived Alternatives. New York: Oxford University Press.

Van Fraassen, B. (1980). The Scientific Image. New York: Oxford University Press.

Turing, A. (1950). Computing machinery and intelligence. Mind, 59, 433-460.

Williams, D. C. (1966). Principles of Empirical Realism: Philosophical Essays. H. Ruja (ed.). Springfield, Illinois: C. C. Thomas. 